\title{
Percutaneous transluminal balloon dilatation of the mitral valve in pregnancy
}

\author{
ROBERT SMITH, DAVID BRENDER, MICHAEL MCCREDIE \\ From the Department of Cardiovascular Medicine, Prince Henry and Prince of Wales Hospitals, and the \\ Department of Medicine, Royal Hospital for Women, Sydney, New South Wales, Australia
}

SUMmaRY Pregnancy can cause life threatening complications in women with mitral stenosis, and there is a substantial risk of fetal death if valvotomy under cardiopulmonary bypass is required. A patient is described in whom pulmonary oedema developed after delivery of her first child by caesarean section 13 months previously. Subsequent cardiac catheterisation showed severe mitral stenosis (valve area $0.96 \mathrm{~cm}^{2}$, valve gradient $12 \mathrm{~mm} \mathrm{Hg}$, pulmonary artery pressure $30 / 16 \mathrm{~mm} \mathrm{Hg}$ ). Before valvotomy could be performed the patient again became pregnant and presented in pulmonary oedema at twenty two weeks' gestation. Medical treatment was unsuccessful and she underwent percutaneous transluminal balloon dilatation of the mitral valve. This increased the valve area to $1.78 \mathrm{~cm}^{2}$ and reduced the transmitral gradient to $6 \mathrm{~mm} \mathrm{Hg}$. The procedure was uncomplicated, and she remained symptom free on no medication. She delivered vaginally at 37 weeks' gestation.

Percutaneous transluminal balloon dilatation of the mitral valve is a safe and effective alternative to mitral valvotomy in pregnancy.

Patients with mitral stenosis have an impaired cardiovascular response to the altered haemodynamic function of pregnancy. The increased cardiac output as well as the tachycardia, ${ }^{1}$ which leads to a shortened diastolic filling period, aggravates the already impeded effective left atrial emptying. This increases the left atrial pressure, especially on exertion, and results in pulmonary oedema. While the tachycardia can often be slowed by $\beta$ blockade, this may not be sufficient, and valvotomy may be required during pregnancy. This often requires cardiopulmonary bypass and is associated with high fetal morbidity and mortality. ${ }^{2}$ The technique of percutaneous transluminal balloon mitral dilatation of the valve offers a safer alternative to surgical valvotomy and we report here a women who had balloon dilatation of the mitral valve at 23 weeks' gestation.

\section{Case report}

This 29 year old woman had a history of rheumatic fever at the age of 11. She had had an uneventful

Requests for reprints to Dr David Brender, The Medical Centre, Second Floor, 64 High Street, Randwick, NSW 2031, Australia. pregnancy 13 months previously. She was delivered by elective caesarean section for obstetric indications (prolonged labour with failure to progress), but immediately after the caesarean section she went into acute pulmonary oedema. She responded to medical treatment with frusemide and digitalis, and three months later underwent cardiac catheterisation, which showed severe mitral stenosis (mitral valve gradient $12 \mathrm{~mm} \mathrm{Hg}$ and mitral valve area $0.96 \mathrm{~cm}^{2}$, pulmonary artery pressure $30 / 16 \mathrm{~mm} \mathrm{Hg}$ ). Ventriculography showed mild mitral regurgitation.

Valvotomy was advised but while she was considering this advice she became pregnant again. She remained well until about 22 weeks' gestation when she presented with a cough and functional class II dyspnoea. Physical examination showed signs of severe mitral stenosis with pulmonary hypertension. A Doppler echocardiogram showed a gradient of 14 $\mathrm{mm} \mathbf{~ g}$ across the mitral valve and a valve area estimated at $1 \cdot 1 \mathrm{~cm}^{2}$, with mild mitral regurgitation. She was admitted to hospital and treated with a diuretic (frusemide $40 \mathrm{mg}$ daily) and a $\beta$ blocker (metoprolol $50 \mathrm{mg}$ twice a day).

Though metoprolol slowed her exertional tachycardia, her symptoms remained severe and she progressed to functional class III. She was intolerant of larger doses of metoprolol because of hypotension 
(supine blood pressure $90 / 70 \mathrm{~mm} \mathrm{Hg}$ ) and postural symptoms during normal mobility in the ward.

After four days it became apparent that she was not responding to medical treatment, and she underwent percutaneous transluminal balloon mitral dilatation of the valve at 23 weeks' gestation.

\section{METHODS}

We successfully dilated the mitral valve under local anaesthesia, using the technique previously described. $^{3}$ A double balloon system was used-one trefoil ( $3 \times 10 \mathrm{~mm}$ diameter) and one monofoil (15 $\mathrm{mm}$ ) balloon. The two balloons were positioned across the mitral valve and inflated twice until a good angiographic result was obtained with obliteration of the indentation made on the balloon by the mitral apparatus. We shielded the uterus with lead and used the shortest practicable screening time. A colloid infusion was given as a rapid bolus at the time of balloon inflation to prevent systemic hypotension.

\section{RESULTS}

The mean gradient across the mitral valve fell from $14 \mathrm{~mm} \mathrm{Hg}$ to $6 \mathrm{~mm} \mathrm{Hg}$ and the mitral valve area increased from $0.95 \mathrm{~cm}^{2}$ to $1.78 \mathrm{~cm}^{2}$. The cardiac output increased from $4.5 \mathrm{l} / \mathrm{min}$ to $5.5 \mathrm{l} / \mathrm{min}$. Ventriculography at the end of the procedure showed that the mild degree of mitral regurgitation remained unchanged. Measurement of oxygen saturations in the right heart showed that there was no shunt from the atrial septostomy. An hour after dilatation transient $(<1 \mathrm{~h})$ right bundle branch block developed. A Doppler echocardiography study done 24 hours after the procedure confirmed the improvement in the valve variables (valve area $1.7 \mathrm{~cm}^{2}$ ). She was discharged from hospital 36 hours after the procedure, and resumed her normal activity. She remained symptom free throughout the remainder of her pregnancy, and delivered vaginally at 37 weeks.

\section{Discussion}

Normal cardiovascular adaptation in pregnancy in patients with a stenosed mitral valve is limited by the associated physiological increase in resting heart rate and a shortened diastolic filling time. This leads to increased left atrial pressure and dyspnoea, especially on exertion, and may threaten both mother and fetus. The tachycardia is of sinus origin and is unresponsive to digoxin because the increased sympathetic tone in pregnancy overrides the vagal effect of digoxin. $\beta$ Blockade is often effective in slowing the exertional tachycardia in these patients, and may allow pregnancy to continue without the need for valvotomy. However, our patient was not able to tolerate a dose of metoprolol sufficient to prevent tachycardia cause unacceptable hypotension developed at a lo dose (50 $\mathrm{mg}$ twice a day). With open valvotom, which requires cardiopulmonary bypass, the fetal mortality ranged from $15 \%$ to $33 \% .{ }^{24}$ Also the risk $\overline{0 f}$ teratogenesis was increased probably due to the use of high dose heparin and hypothermia; such a risk particularly important during the first trimeste $\bar{s}^{2}$ With closed valvotomy, which does not requife cardiopulmonary bypass, fetal mortality was $12 \%$ $15 \%{ }^{4}$; this operation is rarely performed nowadays in Australia.

Experience of percutaneous transluminal balloon dilatation of the mitral valve during pregnancy limited. ${ }^{56}$ The procedure was performed rapidl with minimal screening time and lead shielding of the uterus. It was tolerated well by the patient. The result was excellent, with an increase in valve aref and decrease in valve gradient.

She developed transient right bundle branch blo\& an hour after the procedure. This lasted for about an hour and then the rhythm spontaneously reverted to normal. This effect has been described in otherr patients treated by percutaneous transluminal balloon dilatation of the mitral valve and is probabe caused by transient dysfunction of the right bundle related to the catheters, balloons, and guidewires used during the procedure which can lie against the right bundle. She became almost symptom free immediately on return to the ward, and was dischao ged from hospital 36 hours later, on a tapered dose of metoprolol. She remained symptom free withotit medication, and maintained a normal level of activity until a normal vaginal delivery at 37 weeks.

\section{CONCLUSIONS}

This case illustrates four major points: (a) The life threatening nature of severe mitral stenosis in preg nancy and the urgent need to increase the mitral valve area mechanically. (b) The likelihood that medical treatment will fail because of the altered haemodyn amic state in pregnancy. Conventional treatment fof mitral stenosis is often ineffective. (c) Preconception counselling, which was offered to this patient, is $\underline{\text { ff }}$ vital importance to women with valve disease if the need for emergency procedures is to be avoided. (d Percutaneous transluminal balloon dilatation of the mitral valve is a safe and effective alternative to surgical valvotomy in the management of mitra stenosis during pregnancy.

\section{References}

1 Szekely P, Snaith L. Heart disease and pregnancy Edinburgh and London: Churchill Livingstonf 1974.

2 Vosloo S, Reichart B. The feasibility of closed mitri 

valvotomy in pregnancy. Thorac Cardiovasc Surg 1987;93:675-9.

3 Lock J, Khalilullah M, Shrivasta S. Percutaneous catheter commissurotomy in rheumatic mitral stenosis. N Engl J Med 1985;313:1515-8.

4 Goon M, Raman S, Sinnathuray T. Closed mitral valvotomy in pregnancy. Aust NZ J Obstet Gynaecol 1987;27:173-7.
5 Safian R, Berman A, Sachs B, et al. Percutaneous balloon mitral valvuloplasty in a pregnant woman with mitral stenosis. Cathet Cardiovasc Diagn 1988;15:103-8.

6 Palacios I, Block P, Wilkins G, Rediker D, Daggett W. Percutaneous mitral balloon valvotomy during pregnancy in a patient with severe mitral stenosis. Cathet Cardiovasc Diagn 1988;15:109-11.

\section{Notices}

British Cardiac Society

The Annual General Meeting will take place in Torquay on 22 to 25 May 1990.

\section{Atrial arrhythmias}

A meeting on Current Concepts in the Study and Management of Atrial Arrhythmias will be held in Lyon on 6 to 8 December 1989. For further information write to PMV Congres/Arythmies 89, 130 rue de Clignancourt, 75018 Paris, France. 